Article

\title{
How to Develop the Interdisciplinary Innovation Teams Sustainably?-A Simulation Model from a Perspective of Knowledge Fission and Fusion
}

\author{
Xue Cheng and Qingpu Zhang * \\ School of Management, Harbin Institute of Technology, Harbin 150001, China; chengxue0419@126.com \\ * Correspondence: zhangqingpu@hit.edu.cn; Tel.: +86-187-451-83549
}

Received: 2 August 2018; Accepted: 30 August 2018; Published: 3 September 2018

\begin{abstract}
Knowledge interaction is vital in order that interdisciplinary innovation teams (IITs) develop sustainably. This paper aims to reveal the laws of knowledge interaction in IITs from a perspective of knowledge fission and fusion. Herein, the conceptions of knowledge fission to depict the team member's divergent thinking and knowledge fusion to depict the team member's convergent thinking based on the concept of social physics are proposed. Furthermore, the Markov process describing knowledge interaction is built. The paper uses a case study and a simulation analysis to explain the process of knowledge interaction. The results show that knowledge fission and knowledge fusion have different influences on the various stages of knowledge interaction. To conclude, the model built describes the complex phenomenon of the knowledge interaction process. It reveals the transformation rules from knowledge fission to knowledge fusion in the process of knowledge interaction in IITs. This study also provides new insight for IITs to maintain team sustainability.
\end{abstract}

Keywords: interdisciplinary team; knowledge interaction; knowledge fission; knowledge fusion; Markov

\section{Introduction}

With the increasing complexity of scientific and technological problems in the current time of big science [1], interdisciplinary innovation teams (IITs) have become the main path to solve complex problems [2-4]. Recently, national research policies lay increasing emphasis on problem-oriented research, which also requires the crossing of disciplinary boundaries [5]. As the main force, universities have an irreplaceable role in technological innovation. In particular, some research universities carry major scientific research projects built by the state. Although many interdisciplinary innovation teams have emerged in research universities, most teams cooperated perfunctorily due to the lack of scientific knowledge management methods. The phenomenon of social-loafing or free-riding often occurred in the team [6,7]. These existing problems deviated from the original intention of the IITs. Hence, scholars began to explore the reasons behind successful IITs and how to develop the IITs sustainably. Hare [8] states that the key to the success of a task, especially a complex task, lies in the knowledge communication among team members. The reason for the task's failure in many interdisciplinary teams is not the lack of professional knowledge, but the miscommunication on critical issues [9]. Communication and cooperation within the work group are important for effectiveness [10]. Stewart et al. [11] also show that effective work depends on whether the team can manage the internal members' interaction and the relationship between the team and the external environment. When the innovation team has the necessary external support conditions, the internal interaction has a greater impact on improving team performance. Many studies [12-16] 
have pointed out that knowledge interaction with high quality is the key to solve difficult problems and increase sustainability for IITs. Also, a good project design is important for IITs to communicate accessibly $[17,18]$. Therefore, this article aims to reveal the laws of knowledge interaction in IITs. We aim to explore two particular questions:

- Q1. How do the members in IIT scary out knowledge interaction?

- Q2. How can the knowledge interaction be measured in a reasonable and precise way?

The existing research on the process of knowledge interaction is mainly from the perspectives of knowledge divergence [19-22] or knowledge aggregation [23-25]. Although the necessity to integrate these two aspects has already been raised [26,27], few literature references integrate these two parts to explore their roles in knowledge interaction and few describe the process of knowledge interaction in a quantitative method. Therefore, this study was conducted to overcome the limitations of previous knowledge interaction.

We built a knowledge interaction model from the perspective of knowledge fission and fusion to capture the complex process of knowledge interaction. The use of physical analogies to understand knowledge interaction can be considered as an application of social physics [28]. In this paper, first, we present the concept and characteristics of knowledge interaction in IITs, which are important for the construction of the knowledge interaction process. Then, we propose the conceptions of knowledge fission and knowledge fusion based on the concept of nuclear fission and fusion. The two conceptions both reflect the process of knowledge divergence and knowledge convergence well. Furthermore, we creatively propose the Markov process of knowledge interaction. This model describes the process of knowledge interaction suitably from a dynamic perspective. Moreover, based on case study and simulation, we prove the reality of the proposed model and explore how knowledge fission and knowledge fusion influence the production of a task's prior solution. The remainder of this paper is organized as follows. Section 2 presents a review of the previous literature. Section 3 proposes the conceptions of knowledge fission and knowledge fusion. Section 4 presents the Markov process of knowledge interaction. Section 5 consists of a case study and a simulation analysis. Section 6 discusses and concludes the paper.

\section{Literature Review}

\subsection{Definition of Knowledge Interaction in the IITs}

Knowledge interaction in the IITs belongs to the domain of knowledge management. The interaction body is organized by a group of two or more people from different disciplines with common tasks or goals. Knowledge interaction refers to a process or activity, in which the team members utilize knowledge communication, knowledge sharing, knowledge collision, knowledge integration of critical information, scientific and technological knowledge, skills, as well as experience, to achieve technical innovation and system innovation through experimental research, development activities or empirical practice activities. Hence, knowledge interaction in the IITs has its own characteristics. We generalize as follows.

- Knowledge Heterogeneity

In IITs, knowledge heterogeneity is a salient characteristic because of different education backgrounds, abilities, and experiences among team members. It is a double-edged sword. IITs, as well, have to have breadth and depth of understanding in many functional areas, which is seldom available or possible in one researcher [29]. From the perspective of system engineering, the formation of IITs as a whole appears to be an important factor to solve difficult problems. However, disciplinary differences also can lead to communication problems due to specialized training and terminology and to differences in what is taken for granted by individuals in a given specialty [30]. This requires a tolerance for conflict, persistence, and willingness to allow strongly held opinions to be modified by others with a different perspective [31]. 


\section{- Process Dynamics}

Knowledge interaction among team members cannot be scripted in advance, because the task itself has never been accomplished previously [31]. Due to incomplete information about tasks, IITs face unpredictable interdependencies among members [32,33]. It is uncertain with whom team members will interact next time. Also, the interaction between different members will produce new insights. On the other hand, in the process of knowledge interaction, the introduction of new technology, new equipment or new members needs the team members to communicate intensively [34]. Additionally, the members face higher demands for ongoing learning to make modifications.

\section{- Result Uncertainty}

The dynamic process sometimes leads to conflict [35,36], poor decisions [37] or some other unpredictable results. To conquer these negative outcomes, team members often need to interact repeatedly in order to increase satisfaction. Hence, IITs must design a good work plan to increase efficiency and related outcomes.

\subsection{Knowledge Interaction and Sustainability}

In this paper, sustainability orientation refers to IITs toward sustainable development. In the limited life cycle of the team, how to ensure the vitality of the team through the sustainable development of the team and extend the life cycle of the team is crucial. Johnson et al. define sustainability as the process of ensuring an adaptive prevention system and a sustainable innovation that can be integrated into ongoing operations to benefit diverse stakeholders [38]. Extending this view, we believe that the IITs' sustainability mainly includes four aspects: the ongoing operation of the team, guarantee of the team members' benefit, the adaptive prevention of the team, and the sustainable innovation of the team. It is worth noting that the team's knowledge interaction is critical to the team's sustainability. First, knowledge interaction can guarantee the ongoing operation of the team. Knowledge interaction influences outcomes like mutual understanding, the inclusion of diverse perspectives, and progress toward goals. Long-term cooperation among team members can ensure the sustainable operation of the team $[39,40]$. Second, knowledge interaction can benefit the team members. Team members who participate in the knowledge interaction can not only get the rewards from the team leader after finishing the assignment, but also increase their individual creativity [41], and enrich their own experience [42]. Third, knowledge interaction can ensure the team's adaptive prevention. Some teams flourish, but many fail to sustain their work once the outside environment changes. Through effective knowledge interaction, the team can solve various unpredictable problems in order to adapt the various changes without being dispensed with [43]. Last, sustainable innovation of the team is reliant on knowledge interaction. Through knowledge interactions among diverse team members, IITs can develop combinative capabilities to synthesize and apply the exchanged knowledge within innovation processes [44,45], thus generating a variety of innovative ideas or productions [46]. Hence, in this paper, we explore the path to achieve sustainable development from the perspective of knowledge interaction in IITs.

\subsection{The Process of Knowledge Interaction}

Existing research mainly studies knowledge interaction from two aspects. One aspect is studying the process of knowledge interaction from a specific perspective. The first is from the viewpoint of problem-solving. Some scholars believe that solutions to complex problems represent unique combinations or syntheses of existing knowledge [47-49]. A problem's complexity influences the optimal method of solution search and the optimal means of organizing that search [22]. The second is from the perspective of evaluation. The literature has suggested that evaluations that occur throughout the creative process may affect both idea generation and the identification and retention of creative ideas [50]. Evaluation therefore improves the usefulness, appropriateness, or quality of a group's 
creative ideas [51]. The third is from the perspective of mental models. When a mental model is consistent with the development of cognitive things, it can effectively guide the action. On the contrary, when a mental model does not match the development of cognitive things, it will make the team members' good ideas impossible. Therefore, we must preserve the scientific part of the mental model and improve the unscientific part to achieve good results [52]. The final aspect is from the view of motivated information processing. Some scholars state that team members search and process information, and that through communication, individual-level information processing becomes integrated at the group-level $[53,54]$.

Another aspect of studied knowledge interaction is from the view of process. Some scholars hold the view of knowledge divergence. The process of knowledge divergence is the process by which team ideas are generated. In turn, it can provide a variety of perspectives and ideas for the team to solve problems. Most of the research uses task diversity, problem complexity, and the information sharing mechanism to explain the process of team innovation implementation [19,21,22]. Prior research has shown that shared ideas can stimulate other group members to think of other ideas or categories of ideas $[24,55]$. Researchers generally believe that through conflicting tasks and information sharing, different information views are expressed and collide in the team, thus enhancing the team's creativity. Inversely, others hold the view of knowledge aggregation. Researchers emphasize the focus on the knowledge aggregation process $[23,25,56]$. This process has been conceptualized as a process of convergent decision making that takes place after ideas are generated to improve the quality of the group's creative output [50]. Existing research mainly explains the process of gathering innovative ideas from the perspective of knowledge integration and thinking convergence $[23,57,58]$.

Teams, by their very nature, start off as inefficient work mechanisms [59]. They require periodic feedback about their performance, which is not structured into an academic institution's setting [31]. Brown [17] states that design projects must ultimately pass through three spaces, that are inspiration, ideation, and implementation. For the IITs, producing large numbers of ideas is never the ultimate goal. Instead, what teams are after is a limited number of good ideas to select for further development and, eventually, implementation [60]. Thus, divergent idea generation must be followed by convergent idea selection for creativity to become innovation [26,27]. Therefore, we use the insights of previous research on knowledge divergence and knowledge convergence to provide a theoretical context for the process of knowledge interaction.

\subsection{Social Physics}

Auguste Comte, first used the term "social physics", reflecting his vision of social science as the essential guide and counterpoint to the technical sciences [61]. Nowadays, economists and sociologists, learning and absorbing the methods of modern natural science have become the theoretical source of creative thinking and an important means of methodological innovation $[15,28,62]$. Social physics is just a quantitative social science that applies the principles and methods of physics to explore, interpret, simulate, and seek the law of social behavior [63]. Recently, many studies, such as development kinetic energy of regional economy [64], metaphorical analysis of knowledge as energy [65], the financial wave model for stock indices [66], an ontology for the business model [67], are a rational extension of the natural sciences. These successful applications of interdisciplinary knowledge which emerged in previous literature give us profound inspiration.

\section{Knowledge Fission and Knowledge Fusion}

Inspired by the pioneering statements of group brainstorming [68], divergent thinking [69] and convergent thinking [70], there has been increasing recognition of the fact that actual creative production does not derive from divergent thinking alone, but also requires convergent thinking [25,71,72]. Abundant research effort has been geared towards understanding how the two processes affect knowledge interaction [73]. Based on this literature and our survey on IITs, we found that in the initial stage of knowledge interaction in IITs, team members first put forward plentiful ideas 
aiming at the team's objective. In this process, the collision among ideas inspires team members to generate new ideas. After that, these ideas are filtered, organized, and aggregated as a prior solution for accomplishing the task. This process is complex and dynamic, and there is no model in either cognitive science or knowledge management science that is both realistic and in-depth to systematically describe the process of knowledge interaction. Hence, this paper draws on the conceptions of nuclear fission and fusion to understand knowledge interaction. First, taking on the phenomena of nuclear fission for reference, we propose a conception of knowledge fission to describe the team member's knowledge divergence process of knowledge interaction in IITs. Then, we take the nuclear fusion for reference and propose a conception of knowledge fusion to describe the team member's knowledge convergence process of knowledge interaction in the IITs. Furthermore, we build a Markov process of knowledge interaction to accurately describe the whole knowledge interaction process. Our proposed model reveals the transformation rules from knowledge fission to knowledge fusion in a more precise and intuitive way.

\subsection{Knowledge Fission}

In the early stage of cooperation, team members generate a large number of problem-solving ideas through divergent thinking. This process is very similar to nuclear fission in physics. Nuclear fission [74] in physics refers to a heavy nucleus splitting into two pieces, whose qualities are of the same order of magnitude, accompanied by a release of energy. A large nucleus can split into two or more nuclei of low quality, and release two or three neutrons and tremendous amounts of energy after absorbing a neutron. The neutrons released will then make the other nuclei split again. The process continues and is called a chain reaction.

The occurrence of nuclear fission requires certain prerequisites, such as heavy nuclei and neutrons. Similarly, the occurrence of knowledge fission also requires initial conditions. By analyzing the characteristics of knowledge interaction, we propose four initial conditions of knowledge fission: (a) Each member of the team needs to have a certain level of knowledge in their respective field. (b) Each member should put forward some ideas or suggestions, namely initial seeds related to the problem before knowledge fission. (c) The team takes the generation of enough good ideas or suggestions as the goal at the stage of knowledge fission, and takes the breakthrough of new knowledge, new methods and new technologies or solving complex problems as the ultimate goal. (d) Various systems and mechanisms, such as interest and trust, should be coordinated. This could provide a good system guarantee and interactive platform for the team members to carry on knowledge fission.

In the process of knowledge fission, each member first searches for information (initial seeds) related to the problem within their own discipline. They maintain the diversity of thought of the team so as to develop as rich a set of insights as possible through the articulation of multiple individual perspectives of the researchers [31]. Based on this information and team members' knowledge heterogeneity through brainstorming [68], team members think divergently from multiple angles and directions, and build reasonable knowledge associations within this information; they then generate one or more ideas or suggestions related to the problems. These new ideas or suggestions are absorbed by other members of the team, and stimulate them to produce more ideas or suggestions. This process continues until a sufficient number of good ideas or recommendations have been generated. Different from nuclear fission, the collision of knowledge fission is a mutually inspired process among members, rather than a one-sided approach to inspire others. Through knowledge fission, the team accomplishes the upgraded process from "initial seeds" to "prior seeds".

The process of knowledge fission also releases huge energy, mainly in the following aspects. First, member's knowledge stock increases. Through the mutual absorption of knowledge among team members, the team members' own knowledge stock is enriched and expanded. Members' own implicit knowledge is activated, and bursts into a series of "inspiration sparks". Second, the team's overall knowledge stock increases. The overall knowledge stock of the team increases with the increase of each member's knowledge stock and then the team generates new ideas. Finally, the team's ability to 
solve problems and innovate increases. The interaction between team members' socialized disciplinary structure and creative thinking is the source of creativity in IITs. The knowledge interaction process among team members is also a divergent process of creative thinking. Different innovation knowledge cells are continuously activated and integrated. The production of these creative ideas also increases the team's ability to solve problems.

\subsection{Knowledge Fusion}

After the IITs have obtained a large number of prior seeds through knowledge fission, it is necessary to filter and integrate these seeds, to then get some alternative solutions to the complex problem. This process is very similar to nuclear fusion in physics. Nuclear fusion [75] in physics is that small quality atoms, mainly referring to deuterium and tritium, make nuclei get rid of electrons under certain conditions, so that the two nuclei can attract and collide with each other to produce a new nucleus of heavier property. According to knowledge convergence [25], this paper creatively proposes the concept of knowledge fusion. Knowledge fusion is a process where interactive seeds collide and blend together under the impact of the team's external environment, internal environment and team members' knowledge structure. Through this process, bad seeds can be removed and good seeds can be enriched and improved, so that prior seeds could be upgraded into alternative solutions.

The process of knowledge fusion also releases huge energy, mainly reflected in the two aspects. The first is the team can research a consensus. IITs' members reach a general cognition on some knowledge and establish an orderly association between different knowledge. The other aspect is the emergence of innovative knowledge. On the basis of knowledge fission to generate innovative knowledge, knowledge fusion generates new and creative ideas and makes these ideas more concise and focused.

Knowledge fusion occurs when two or more interactive seeds collide together. Often, an alternative solution requires many instances of knowledge fusion. It is worth noting that, due to the different level of collisions among interactive seeds, the effects of fusion can also be different. The specific states are described as follows. First, interactive seeds cannot fuse together and still maintain their original state. Second, interactive seeds can combine simply after the collision. Third, one side of the interactive seeds stimulates the other side of the interactive seeds and makes them produce new mutations. Then the old and new interactive seeds blend together. Finally, after the collision, both sides of the interactive seeds can critically absorb each other's knowledge, mutual complement, improve, inherit, and innovate together. Additionally, they could then produce a new and creative mutation. Through knowledge fission, enough interactive seeds could be produced and then through knowledge fusion, these interactive seeds blend together to form the alternative solutions. This "divergent-convergent thinking" process is similar to the process in which people solve problems in practice.

\section{Markov Process of Knowledge Interaction}

\subsection{The Process of Knowledge Interaction}

The whole process of knowledge interaction in the IITs is shown in Figure 1. We can see that, at the first stage, team members first search for initial seeds related to the problem within their own discipline. At the second stage, team members carry on knowledge fission. Through knowledge fission, the initial seeds change into the prior seeds. The third stage is knowledge fusion. Through this process, the prior seeds upgrade into the alternative solutions. However, we still cannot ensure that the alternative solutions are perfect and meet the initial objectives set by the IITs. So we need to further test and select alternative solutions and amend the seeds that do not meet the requirements. If the alternative solution passes the test, it will become the prior solution. Otherwise the team members will analyze the reasons of failure. If the interactive seeds deviate far from the initial expectation after the knowledge fusion, then the production of the alternative solution has failed. If the reasons of not passing the test are caused by the lack of team effort and the alternative solution has room to be 
improved, then the IITs will carry on with knowledge fission and knowledge fusion again until the alternative solutions pass the test and form the final prior solutions. The whole process of knowledge interaction is complex and dynamic, and influenced by various factors. This article only discusses the following important aspects. As shown in Figure 1, the whole process is influenced by the team context, including team culture, team mechanism, and the amount of information ambiguity and uncertainty. The process of knowledge fission is affected by the following factors.

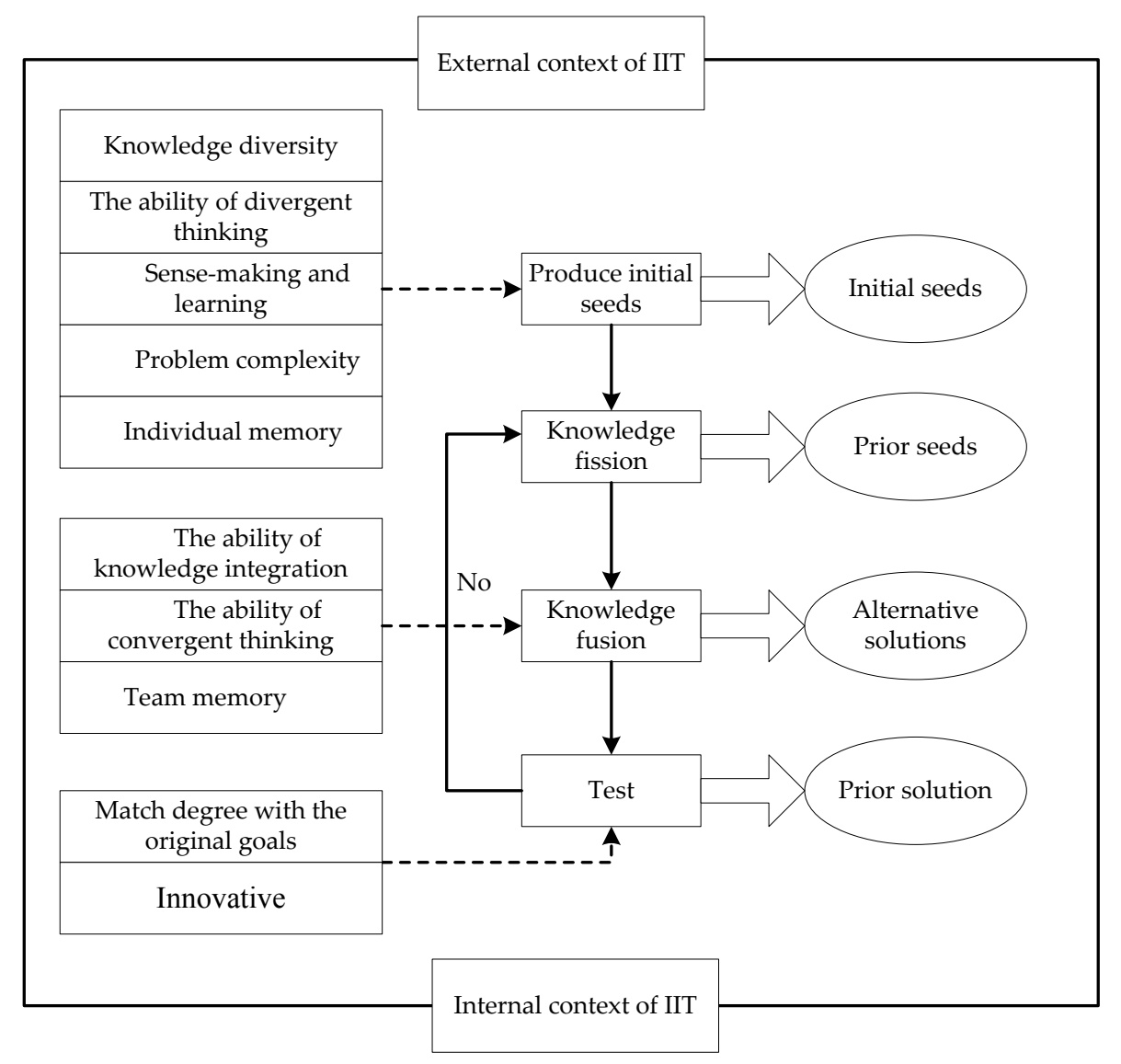

Figure 1. The process of knowledge interaction (IIT-interdisciplinary innovation team).

\section{- Knowledge diversity}

Compared with the ordinary innovation teams, the biggest advantage of the IITs is to be able to bring together team members with different professional backgrounds and knowledge skills, which will enrich the team's information resources and provide diverse angles and ideas as samples for the team to consider the problem and find solutions [14,20]. Teams whose members have diverse knowledge categories may produce more original ideas [24] and teams with members from different ethnic backgrounds may produce higher quality ideas [76]. Evidence suggests that knowledge diversity creates individual and group processes associated with divergent thinking [77,78]. Thus, knowledge diversity has an important influence on knowledge fission.

- The ability of divergent thinking

Divergent thinking is an important driver of knowledge fission. Compared with homogeneous groups or individuals, IITs have an advantage with divergent thinking because novel ideas can result when one group members' idea stimulates a novel connection in another's associative hierarchy [58,79]. Through divergent thinking, team members can come up with all the ideas related to the problem, which provide a guarantee for the solution to the problem. 
- Sense-making and learning

Weick states that, in the process of sense-making, something that preserves plausibility and coherence, something that is reasonable and memorable, something that embodies past experience and expectations, something that captures both feeling and thought, something that is fun to contrast [80]. This kind of sense-making and learning is exactly what the team needs to carry out knowledge interaction, so that members can better capture each other's ideas in the process of knowledge fission, and then stimulate the generation of members' own interaction seeds.

- Problem Complexity

A problem's complexity influences the optimal method of solution search and the optimal means of organizing that search [22]. Depending on the complexity of the problem, team members choose other different members to interact according to their needs, which in turn affects the search path of the interactive seeds and the generation of different interactive seeds. The more complex the problem, the more the members are motivated to explore the problemed team will generate more interactive seeds.

- Individual Memory

To generate ideas to share in the team, team members are presumed to search their memory for relevant domains and tap them for relevant ideas. After tapping ideas in one domain the search continues for other domains or categories of ideas [81,82]. Individual memory is the basis for team members to engage in knowledge fission. It provides the necessary conditions for members to generate interactive seeds.

The process of knowledge fusion is affected by the following factors.

- The ability of knowledge integration

Knowledge integration is the process of synthesizing multiple views or ideas into a common perspective. When diverse team members combine their underlying perspectives into a shared view of a problem and then generate solutions, they have a higher chance of developing a breakthrough idea than when they use their diversity to stimulate idea generation directly [23]. Through knowledge integration, interdisciplinary teams can integrate some ideas to form several perspectives, which provide favorable conditions for the team's next choice.

- The ability of convergent thinking

Convergent thinking occurs when team members stimulate one another's divergent thinking and their individual ideas are aggregated into the group's creative output $[57,58]$. Convergent thinking underlies the process of knowledge fusion because it involves narrowing alternatives toward a correct or best answer $[25,83]$. The convergent thinking not only enables team members to bring together good ideas, but also filters out poor ideas $[3,51]$. Hence, convergent thinking is the important driver of knowledge fusion.

- Team memory

Organizational memory is the shared recognition of collective experience, and it is re-enacted every time organizational members interpret their current situation [84]. For the IITs, there exists team memory. Team members will use this re-enacted organizational memory as a signpost in making sensible and appropriate choices about the interactive seeds $[85,86]$. Hence, team memory is flexible enough to serve as a resource that team members can draw upon when facing practical problems.

The process of testing is determined by the following two aspects. 
- Match degree with the original goals

Because the interactive seeds were obtained by team members' divergent thinking, some ideas inevitably deviate from the original mission objectives. This test process entails validating ideas against task criteria [87] to choose options that may be implemented.

- Innovative

For the IITs, the prior solution designed by the team not only solves difficult problems well, but also is innovative [3,51]. In this way, the IITs can be competitive and continue to operate.

Next, we analyze how the knowledge fission and knowledge fusion influence knowledge interaction based on the Markov state transition process.

\subsection{Markov Process of Knowledge Interaction}

From the above analysis, we can regard the problem of knowledge interaction as a random process. Although the actions (knowledge fission and fusion) taken by team members have been determined as shown in Figure 1, interactive seeds can be in different states at different times. We do not know how the interactive seeds transfer among different states under knowledge fission and fusion. The probability distribution of the state of the current interaction seeds is only related to the state of the previous period, and has nothing to do with the earlier state. Also, the previous state is only related to the earlier state. Recursively, the current state is a step-by-step accumulation of all the previous states. The previous state is also the accumulation of all the earlier states. Hence, the current state is only related to the previous state. In this sense, the process of knowledge interaction is both a Markov process and the accumulation of knowledge. Therefore, we can use the Markov process to analyze the current states and predict future states of interactive seeds. The state transition process of knowledge interaction is shown in Figure 2. The state A, B, C, D represent interactive seeds in different states, initial seeds, prior seeds, alternative solution, and prior solution. The arrows represent transitions among the four states.

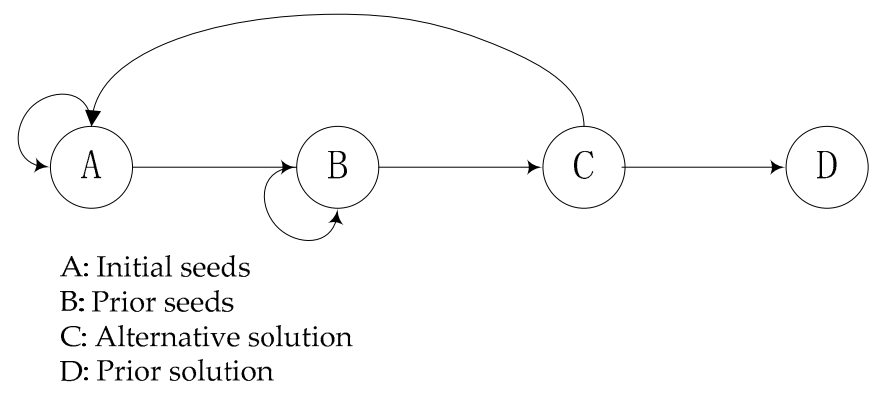

Figure 2. The process of state transition.

The process of knowledge interaction $\{X(t), t \in T\}$ is the Markov process. $T$ is the cycle of knowledge interaction. The process of knowledge interaction $\left\{x\left(t_{n}\right)\right\}=\left\{x\left(t_{1}\right), x\left(t_{2}\right), x\left(t_{3}\right), x\left(t_{4}\right)\right\}$ respectively indicates that the knowledge interaction seeds are in the above four states. If knowledge interaction seeds are in the state $i$ at step $n-1$, and in the state $j$ at step $n$, then the one-step transfer probability of the knowledge interaction seed is $p\left\{x_{n}=j \mid x_{n-1}=i\right\}$. In the process of knowledge interaction, this one-step transfer probability does not change with time (stability hypothesis), that is $p\left\{x_{n}=j \mid x_{n-1}=i\right\}=p\left\{x_{1}=j \mid x_{0}=i\right\}=p_{i j},(n \geq 0)$. Then the probability of transition among the various states of the knowledge interaction seeds is 


$$
p=\left(p_{i j}\right)=\left[\begin{array}{llll}
p_{11} & p_{12} & p_{13} & p_{14} \\
p_{21} & p_{22} & p_{23} & p_{24} \\
p_{31} & p_{32} & p_{33} & p_{34} \\
p_{41} & p_{42} & p_{43} & p_{44}
\end{array}\right]
$$

- Measurement of $p_{1 j}$

$p_{1 j}$ is the probability of knowledge interaction seeds moving from State A to the other three states, respectively? From the state transition process of knowledge interaction and the Markov stability hypothesis, we get that $p_{13}=0, p_{14}=0, p_{11}+p_{12}=1 . p_{12}$ is the transition probability of interaction seeds changing from State A to State B, which is affected by knowledge fission? As is analyzed in Section 4.1, knowledge fission is mainly influenced by knowledge diversity, the ability of divergent thinking, sense-making and learning, problem complexity, and individual memory, represented by $M_{1}$, $M_{2}, M_{3}, M_{4}, M_{5}$ respectively. $M_{1}, M_{2}, M_{3}, M_{4}, M_{5}$ can be evaluated by authoritative experts inside or outside the team. Let $W_{m}=\left(w_{1 m}, w_{2 m}, w_{3 m}, w_{4 m}, w_{5 m}\right)$ be a weight vector for the five aspects of influencing factors. The weight vector represents the relative importance of the factors perceived by experts. So the formula $p_{12}$ is as follows:

$$
p_{12}=\frac{\sum_{i=1}^{5} w_{i m} M_{i}}{\sum_{i=1}^{5} \max \left\{M_{i}\right\}}
$$

where $M_{i} \in[0,1]$.

- Measurement of $p_{2 j}$

$p_{2 j}$ is the probability of knowledge interaction seeds moving from State B to the other three states, respectively. From the state transition process of knowledge interaction and the Markov stability hypothesis, we get that $p_{21}=0, p_{24}=0, p_{22}+p_{23}=1, p_{23}$ is the transition probability of interaction seeds changing from State B to State C, which is affected by knowledge fusion. As is analyzed in Section 4.1, knowledge fusion is influenced by the ability of knowledge integration, the ability of convergent thinking, and team memory, represented by $G_{1}, G_{2}, G_{3}$ respectively. $G_{1}, G_{2}, G_{3}$ can be evaluated by authoritative experts inside or outside the team. Let $W_{g}=\left(w_{1 g}, w_{2 g}, w_{3 g}\right)$ be a weight vector for the three aspects of influencing factors. The weight vector represents the relative importance of the factors perceived by experts. So the formula $p_{23}$ is as follows:

$$
p_{23}=\frac{\sum_{i=1}^{3} w_{g m} G_{i}}{\sum_{i=1}^{3} \max \left\{G_{i}\right\}}
$$

where $G_{i} \in[0,1]$.

- Measurement of $p_{3 j}$

$p_{3 j}$ is the probability of knowledge interaction seeds moving from State $C$ to the other three states, respectively. From the state transition process of knowledge interaction and the Markov stability hypothesis, we get that $p_{32}=0, p_{33}=0, p_{31}+p_{34}=1, p_{34}$ is the transition probability of interaction seeds changing from State $C$ to State $D$, which is affected by the test process. We test the alternative solutions from two aspects: the match degree with the original goals and the innovation, represented by $Q_{1}, Q_{2}$, respectively. $Q_{1}, Q_{2}$ can be evaluated by authoritative experts inside or outside the team. Let $W_{q}=\left(w_{1 q}, w_{2 q}\right)$ be a weight vector for the two aspects of the influencing factors. The weight 
vector represents the relative importance of the factors perceived by experts. So the formula $p_{34}$ is as follows:

$$
p_{34}=\frac{\sum_{i=1}^{2} w_{q m} Q_{i}}{\sum_{i=1}^{2} \max \left\{Q_{i}\right\}}
$$

where $Q_{i} \in[0,1]$.

\subsection{Measurement of $p_{4 j}$}

State $\mathrm{D}$ is an absorbing state. The interactive seeds entering into this state will always stay in it. It is also the optimal state of knowledge interaction we expect to achieve. Hence, $p_{41}=p_{42}=p_{43}=0$, $p_{44}=1$.

\section{Case Study and Simulation}

This study uses a combination of case study and simulation analysis to validate the proposed model framework. Through case analysis, the real existence and rationality of the model proposed has been proved. Furthermore, we use simulation analysis to explore the influence of different levels of knowledge fission and knowledge fusion on the whole knowledge interaction process, which is unlikely to occur simultaneously in one case.

\subsection{Case Study}

\subsubsection{Sample Selection}

We choose the case from three factors. (a) The team is limited to interdisciplinary team. (b) The team is an innovative team and has some innovative achievements. (c) Information is easy to obtain. Combining these three criteria, we finally selected the "Small Satellite" interdisciplinary innovation team of Harbin Institute of Technology as the object of case study. An in-depth analysis of the evolution of the knowledge interaction about this team can help us to understand how IITs carry on knowledge interaction, and thus promote team innovation, which has a high degree of relevance to the research in this paper.

Founded in 1995, the small satellite interdisciplinary team in H University was engaged in micro-satellite research. Now the team has 18 researchers (including more than 10 Yangtze River scholars, doctoral supervisors, and professors) and nearly a hundred Ph.D students and postgraduates. The team members come from different related disciplines, such as aircraft design, mechanics, information and communication engineering, control theory and application, computer, man-machine environment engineering, automation and so on. This research team has successively undertaken the National "863" project, Natural Science Foundation of China and more than 50 national basic research programs. Now this team is striving to explore a new way for Chinese micro-satellite technology development and progress. After the successful research of "Test-satellite-1", "Test-satellite-3", and "Kuaizhou-1", this team has now become an outstanding team engaged in small satellite technology research in Chinese universities. We track and investigate here one of the team's research projects for half a year. The project took the chief designer $\mathrm{Xu}$, deputy chief engineering Cao, and deputy commander Kong as the core leadership and consists of thirty members from different disciplines.

\subsubsection{Data Collection}

This study focuses on the evolution of knowledge interaction among team members through follow-up interviews and document analysis of the research object.

Semi-structured interview is the main data collection method used in this study. The researchers interviewed the respondents in depth, and quickly sorted out the materials. Through the team's 
discussion and literature comparison, the constructs and specific ideas were clarified. In order to have enough time to organize, digest, and absorb the data, the researchers negotiated with the team to arrange the interview with as many as possible, and each interviewee was interviewed separately. In the survey, when the information provided by the respondent was in conflict or imperfect, the researchers would check and supplement it in time. Based on this research design, the researchers conducted six interviews and interviewed 20 people. The researchers were divided into two groups of two members, and separately coded the data collected based on a preliminary coding scheme. Then the researchers were compared between groups and verified each other's coding. If there was an inconsistent view on the code, it was solved by discussion or by finding a third party to solicit opinions. According to the theoretical model proposed above, by using content analysis methods for different sources of data and coding with specific interaction processes, the researchers gradually summarized subclasses of knowledge interaction. On the basis of these sub-categories, through reciprocating contrast, the interaction process model is formed.

In addition to in-depth interviews, researchers also collected data through second-hand data, which improved the validity of the case by data's complementation and cross validation [88]. The second-hand data mainly included online information, internal meeting minutes of the team, etc. Through the above method, the authenticity of the data provided by the interviewee was verified.

\subsubsection{Data Coding and Analysis}

The research on the satellite is a large and complex project, which needs to go through design, analysis, simulation, testing, and a series of processes. The process of satellite design is the most important and core part, and a large number of innovative ideas are produced in this process. Through in-depth analysis of the data, we find that the knowledge interaction of the small satellite design mainly includes five stages: the formation of the primary idea, the knowledge divergence, the knowledge convergence, and the test stage. Table 1 lists the main features and examples of evidence at each stage of knowledge interaction.

1. Formation of the primary idea. The purpose of this stage is mainly to let team members express different opinions. Based on their past experience, team members unreservedly expressed their views.

2. Knowledge divergence. At this stage, all involved personnel can form discussion groups, discuss a problem together, and engage in full knowledge interaction. Through dialogue, information feedback, collisions, and even conflicts, team members are encouraged to generate more problem-solving ideas. This process is consistent with the knowledge fission phase in the model.

3. Knowledge convergence. This stage is mainly to establish a consensus of the team and organize the knowledge of different disciplines in an orderly manner. Taking into account the scientific and cost, the team removed some poor ideas. The team continued to enrich and refine valuable ideas, integrated a large number of ideas, and focused the team's ideas. This process is basically consistent with the knowledge fusion phase described in the model.

4. Test. At this stage, some alternatives are tested through experiments. The solution passing the test became the prior solution. If the alternative fails the test, the team will analyze the reason why. If the alternative has potential to optimize, the team members will revisit it to see if they can get a satisfactory solution. 
Table 1. The main features and examples of evidence at each stage of knowledge interaction.

\begin{tabular}{|c|c|c|}
\hline Stage & Feature & Examples of Evidence \\
\hline $\begin{array}{l}\text { Formation of the } \\
\text { primary idea }\end{array}$ & $\begin{array}{c}\text { Expression of } \\
\text { different opinions }\end{array}$ & $\begin{array}{l}\text { "I have a lot of professional things, including formulas. After I } \\
\text { had written them, everyone was wide-eyed and felt this } \\
\text { couldn't solve the problem. But in the end, everyone thought it } \\
\text { was a natural, clever thing." }\end{array}$ \\
\hline $\begin{array}{l}\text { Knowledge } \\
\text { divergence }\end{array}$ & $\begin{array}{l}\text { Brainstorm, } \\
\text { Knowledge collision, } \\
\text { inspiration }\end{array}$ & $\begin{array}{l}\text { "Our team has a meeting every Wednesday afternoon to discuss } \\
\text { the problems that everyone has encountered this week"; } \\
\text { "The advantage that our team has maintained for a long time is } \\
\text { that when we discuss a certain issue, we can express our } \\
\text { opinions on a certain issue without worrying about position or } \\
\text { age"; "New inspiration was often produced when others spoke. } \\
\text { One of his words just inspired me." "When the internal opinions } \\
\text { are inconsistent, the team leader often encouraged everyone to } \\
\text { say, this is not to be feared, it is also the routine in the } \\
\text { development of things, never unified to unity". }\end{array}$ \\
\hline $\begin{array}{l}\text { Knowledge } \\
\text { convergence. }\end{array}$ & $\begin{array}{l}\text { Establishment of } \\
\text { team consensus }\end{array}$ & $\begin{array}{l}\text { "In the meeting, we had a special person in charge to record the } \\
\text { ideas put forward by everyone, and then through discussion, } \\
\text { removed the ideas that were not realistic"; "We continued to } \\
\text { explore the ideas we retained and linked some ideas to see if we } \\
\text { could find a breakthrough in the problem."; "When discussing } \\
\text { the issue, some members put forward their own new opinions } \\
\text { sometimes." }\end{array}$ \\
\hline Test & $\begin{array}{l}\text { Test of the design } \\
\text { plan }\end{array}$ & $\begin{array}{l}\text { "This design encountered some problems during the } \\
\text { experiment. In the next week's regular meeting, we will discuss } \\
\text { the plan in detail to see where the problem lies." }\end{array}$ \\
\hline
\end{tabular}

\subsection{Simulation and Results}

The main question in this section is "Can we forecast the change of knowledge interaction seeds by using our proposed model?" To answer this question, we make the effort to conduct simulations based on Matlab to explore the impact of knowledge fission and knowledge fusion on the knowledge interaction process.

\subsubsection{Influence of Knowledge Fission on the Knowledge Interaction Process}

This section mainly explores the influence of knowledge fission on the knowledge interaction process. avg- $\mathrm{m}$ is the average value of knowledge fission. Figure $3 \mathrm{a}$ shows the change of interaction seeds in State A over time. We can see that the interaction seeds gradually decrease in the three cases, avg- $\mathrm{m}=0.2$, avg- $\mathrm{m}=0.5$ and avg- $\mathrm{m}=0.8$. And when avg- $\mathrm{m}=0.2$, the interaction seeds are more than avg- $\mathrm{m}=0.5$ and avg- $\mathrm{m}=0.8$. This shows that the bigger the knowledge fission value, the more favorable it is for the interactive seed transfer from State A to State B.

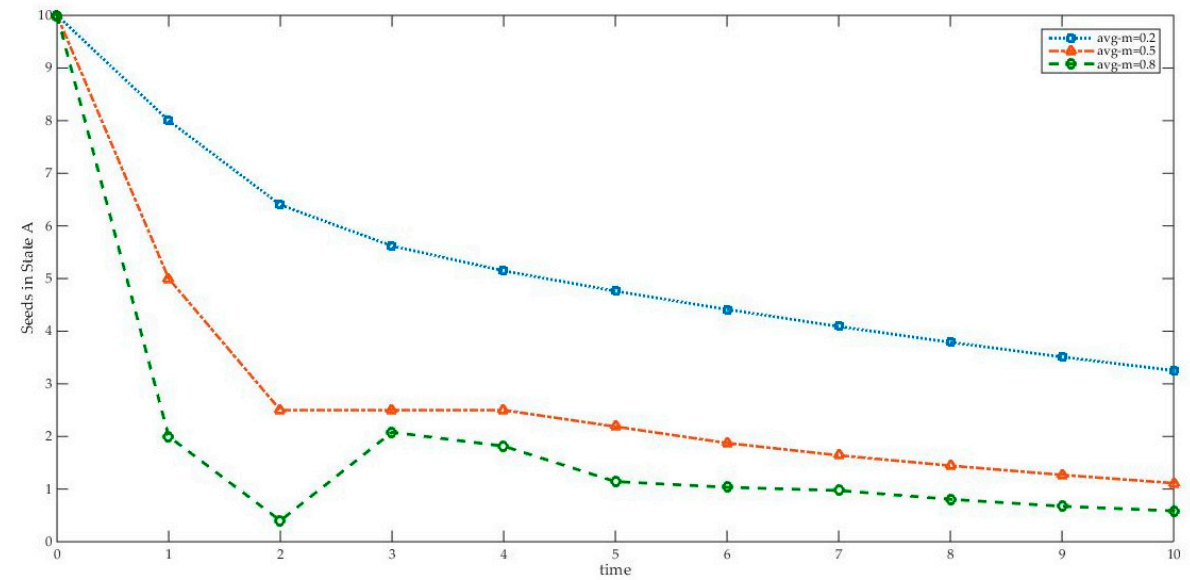

(a)

Figure 3. Cont. 


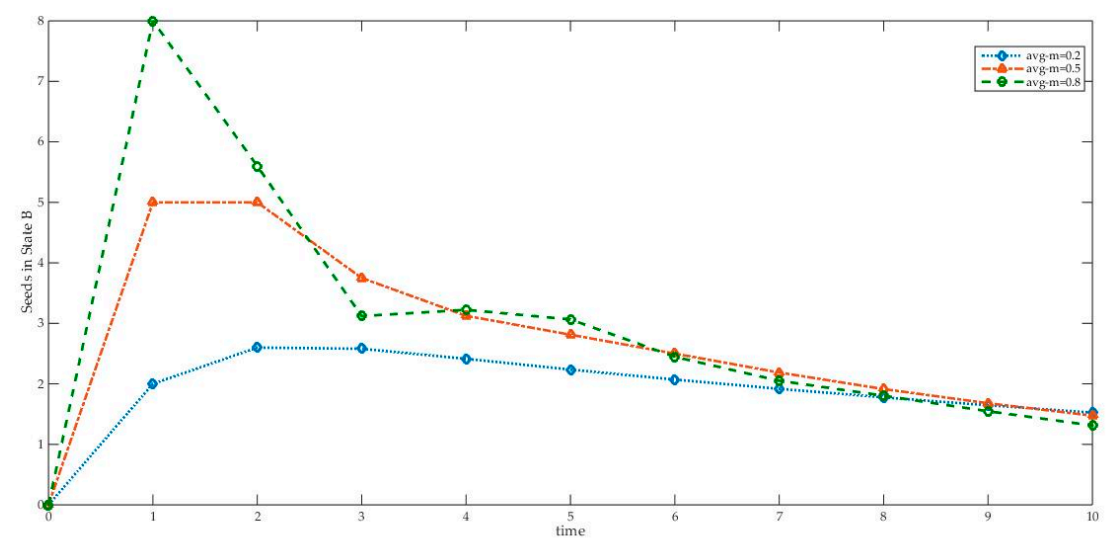

(b)

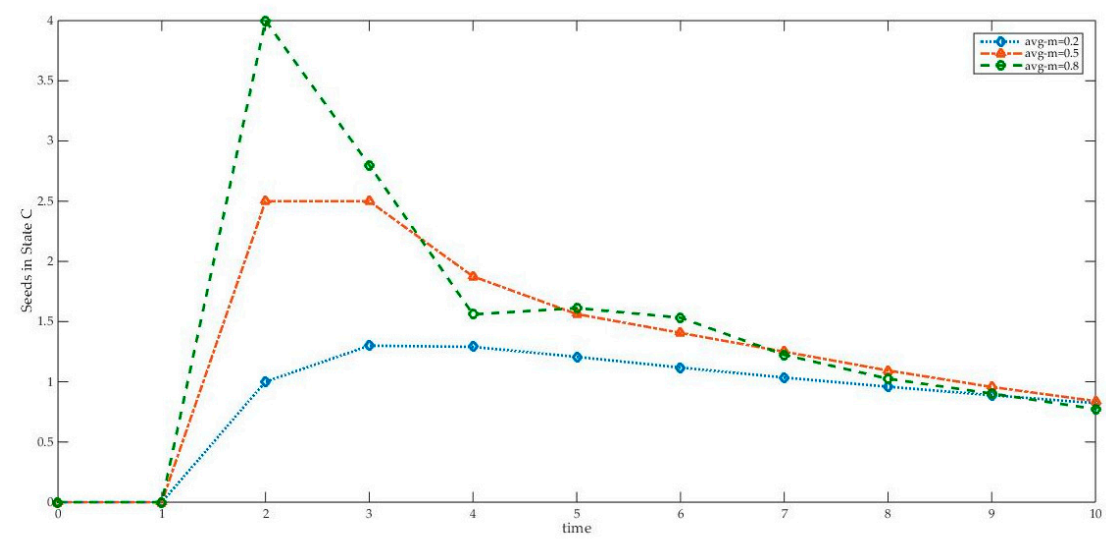

(c)

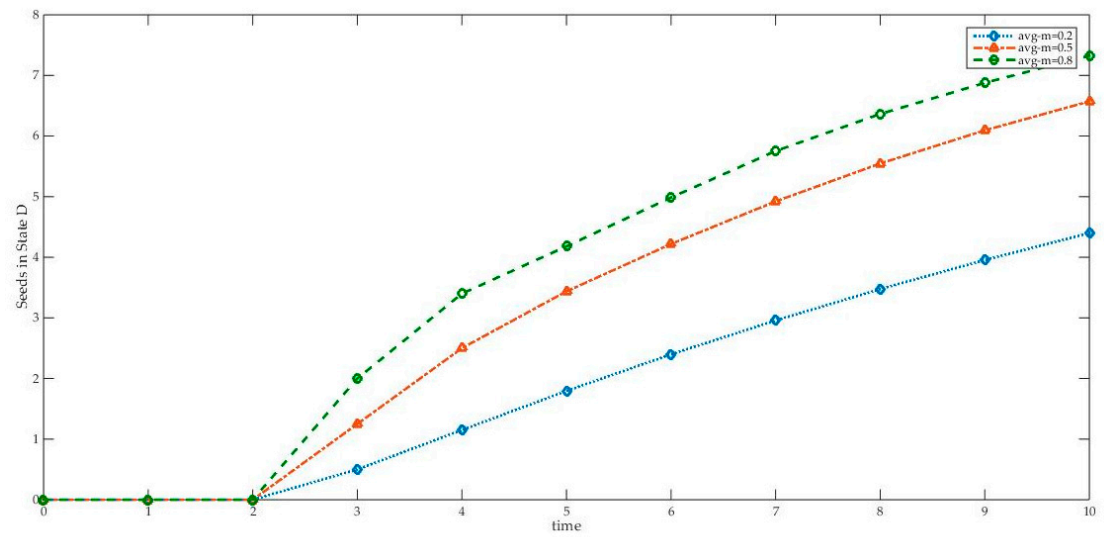

(d)

Figure 3. Influence of knowledge fission on interaction seeds: (a) Changes of interaction seeds in State A; (b) changes of interaction seeds in State B; (c) changes of interaction seeds in State C; (d) changes of interaction seeds in State D. 
Figure $3 \mathrm{~b}$ shows the change of interaction seeds in State B over time. We can see that, the interaction seeds increase first and then gradually decrease. In the initial period, when avg-m $=0.8$, the number of interaction seeds changes sharply. Interaction seeds are more than avg-m $=0.2$ and avg- $\mathrm{m}=0.5$ taking off at $\mathrm{t}=1$. However, compared with avg- $\mathrm{m}=0.5$, interaction seeds are less, taking off $t=3$. This means that if the value of knowledge fission is too large, more prior seeds cannot be obtained because of knowledge heterogeneity, which prevents communication among team members. At the final stage, the number of interaction seeds in state $B$ has little difference between avg- $m=0.2$, avg- $\mathrm{m}=0.5$ and avg- $\mathrm{m}=0.8$.

Figure $3 c$ shows the change of interaction seeds in State $C$ over time. We can see that all the interaction seeds increase first and then gradually decrease in the three cases. It is clear that when avg- $\mathrm{m}=0.8$, the interaction seeds are dramatically larger than that of avg- $\mathrm{m}=0.2$ and avg- $\mathrm{m}=0.5$ taking off at $t=2$. At the final stage, the number of interaction seeds in state $\mathrm{C}$ has little difference between avg- $\mathrm{m}=0.2$, avg- $\mathrm{m}=0.5$ and avg- $\mathrm{m}=0.8$.

Figure $3 \mathrm{~d}$ shows the change of interaction seeds in State $\mathrm{D}$ as time proceeds and when avg-m $=0.8$, interaction seeds are more than avg-m $=0.2$ and avg-m $=0.5$ Figure $3 a-d$ reveals that, as time proceeds, interaction seeds gradually transfer from State A, State B, and State C into State D. This reveals that knowledge fission promotes the production of the prior solution.

\subsubsection{Influence of Knowledge Fusion on the Knowledge Interaction Process}

This section mainly explores the influence of knowledge fusion on the knowledge interaction process. avg-g is the average value of the knowledge fusion. Figure 4a shows the change of interaction seeds in State A over time. We can see that the interaction seeds gradually decrease in the three cases. At the final stage, there is little difference between the three cases. This means knowledge fusion has little influence on the knowledge interaction seeds changing from State A to State B.

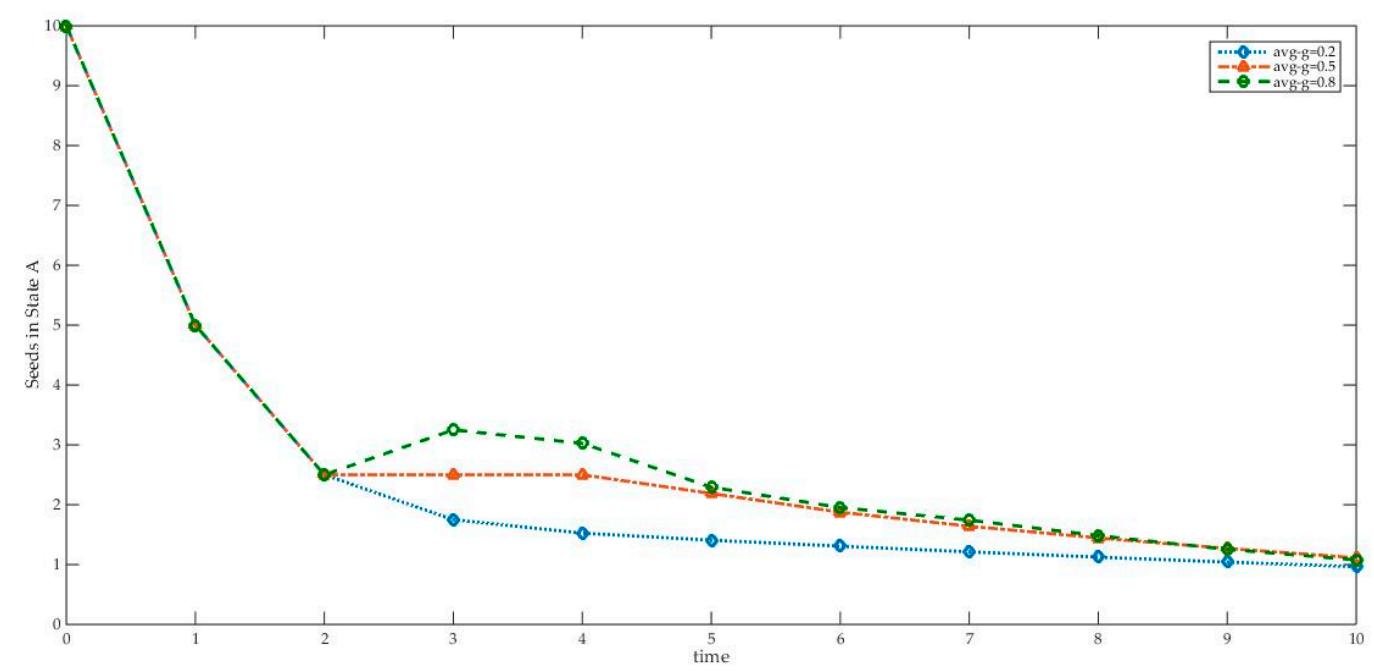

(a)

Figure 4. Cont. 


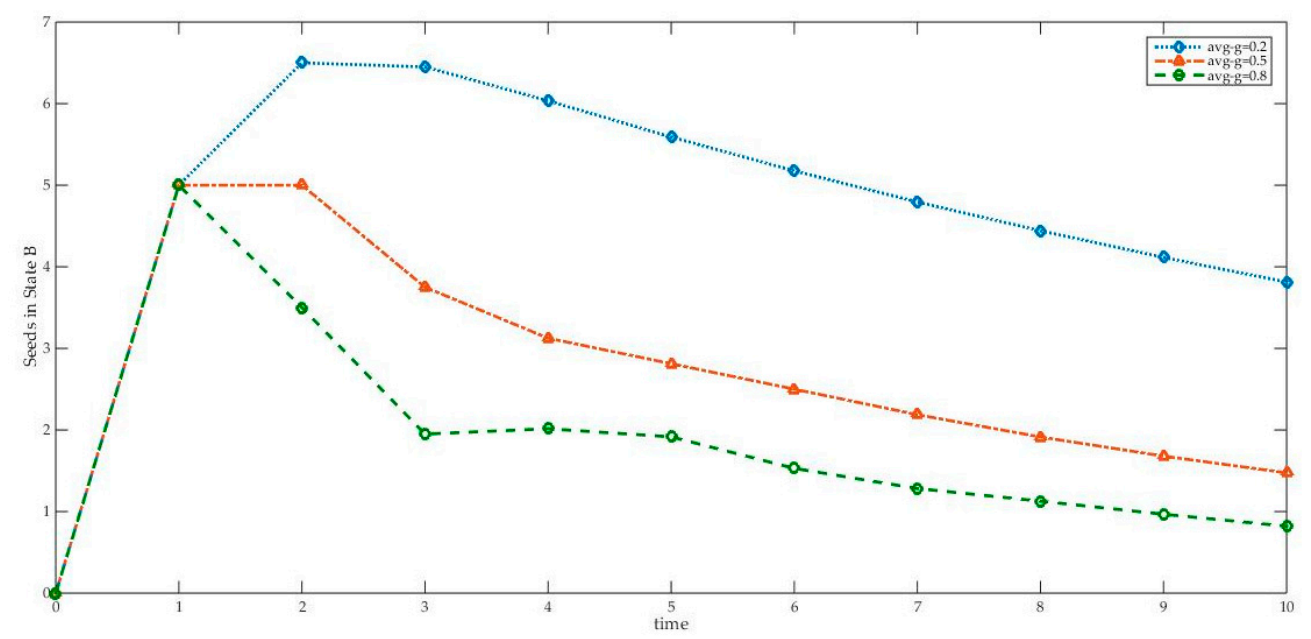

(b)

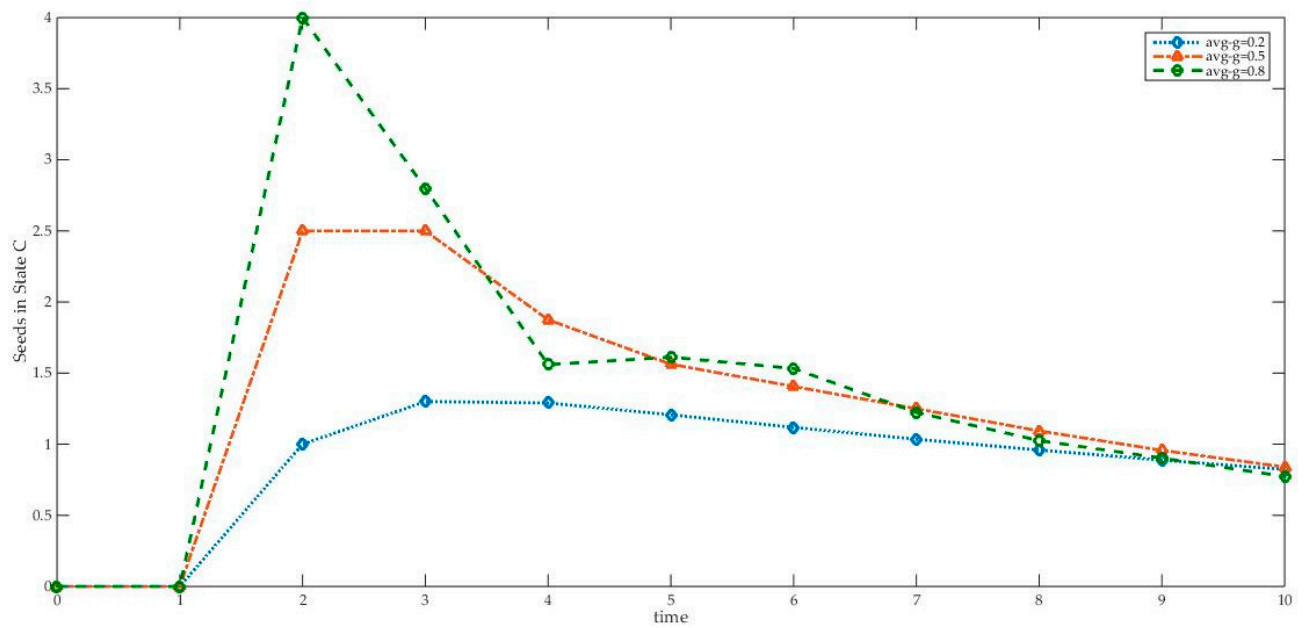

(c)

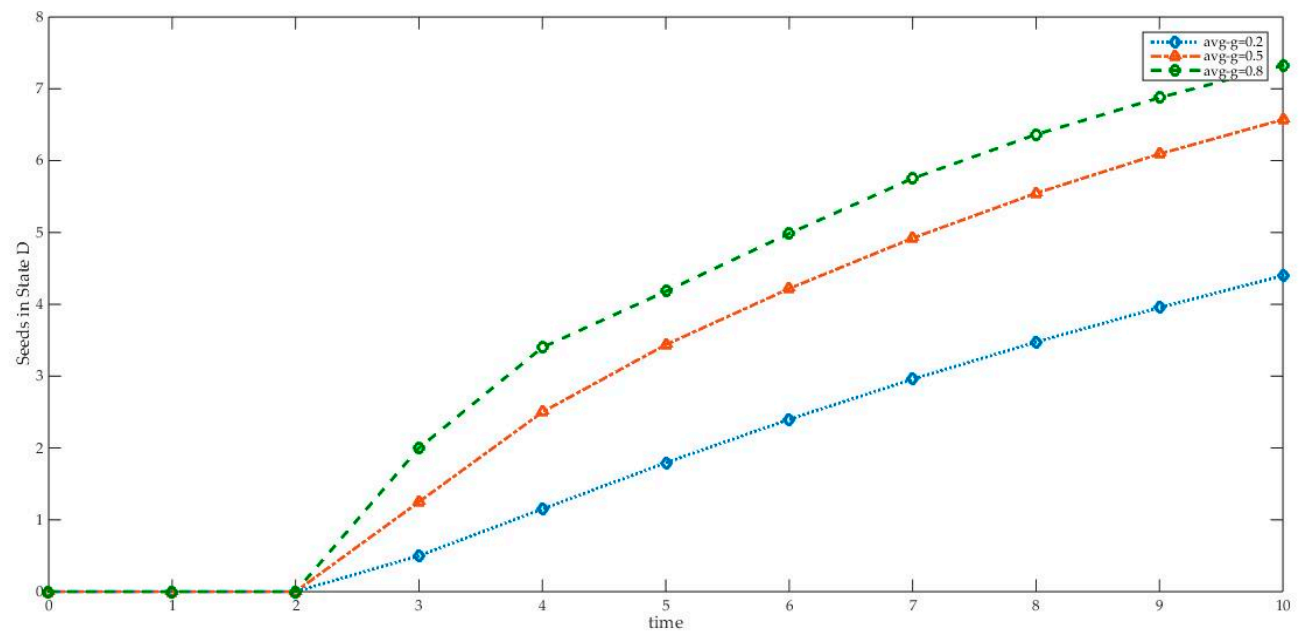

(d)

Figure 4. Influence of knowledge fusion on interaction seeds: (a) Changes of interaction seeds in State A; (b) changes of interaction seeds in State B; (c) changes of interaction seeds in State C; (d) changes of interaction seeds in State D. 
Figure $4 \mathrm{~b}$ shows the change of interaction seeds in State B over time. All the interaction seeds increase first and then gradually decrease in the three cases. When avg- $\mathrm{m}=0.2$, the interaction seeds are more than avg- $\mathrm{m}=0.5$ and avg- $\mathrm{m}=0.8$ at $\mathrm{t}=2$. It means that the interaction seeds in State $\mathrm{B}$ transfer into State $C$ with the increase of the value of knowledge fusion.

Figure $4 \mathrm{c}$ shows the change of interaction seeds in State $C$ as time proceeds. All the interaction seeds increase first and then gradually decrease in the three cases. At the initial stage, when avg-m $=0.8$, the number of interaction seeds changes sharply. Interaction seeds are more than avg- $\mathrm{m}=0.5$ and avg- $\mathrm{m}=0.2$ taking off at $\mathrm{t}=2$. However, compared with avg- $\mathrm{m}=0.5$, interaction seeds are less, taking off $t=4$. This reveals that if the value of the knowledge fusion is too large, more alternative solutions cannot be obtained. At the final stage, there is little difference between the three cases.

Figure $4 \mathrm{~d}$ shows the change of interaction seeds in State $\mathrm{C}$ as time proceeds. When avg- $\mathrm{m}=0.8$, interaction seeds are more than avg- $\mathrm{m}=0.5 \mathrm{and}$ avg- $\mathrm{m}=0.2$. Figure $4 \mathrm{a}-\mathrm{d}$ show that, as time proceeds, interaction seeds gradually transfer from State A, State B, and State C into State D. It reveals that, in the short term, knowledge fusion promotes the production of a prior solution.

\section{Discussion and Conclusions}

\subsection{Theoretical Contributions}

The theoretical contributions related to knowledge interaction in IITs are reflected by three aspects. First, we define the conception of knowledge interaction in IITs. The characteristics of knowledge interaction in IITs, knowledge heterogeneity, process dynamics, and result uncertainty, have a significant influence on the knowledge interaction process.

Second, this paper contributes to the literature of application of social physics. We propose the conceptions of knowledge fission and knowledge fusion based on nuclear fission and fusion in physics. Knowledge fission reflects the process of thinking divergence among team members while knowledge fusion reflects the process of thinking convergence among team members. Through the analysis of knowledge fission and knowledge fusion, we find that they are ubiquitous in IITs. Our research is a creative application of social physics.

Third, we are extending the literature on the knowledge interaction model. Though some literature holds the view that, for creativity to become innovation, divergent idea generation must be followed by convergent idea selection [27], there is no literature on integrating these two processes together. To quantitatively explore the process of knowledge interaction, this paper propose the knowledge interaction model based on Markov process. We explore the process of the initial seeds undergoing knowledge fission, knowledge fusion, testing, and finally forming a prior solution. It describes the complex process of knowledge interaction objectively and reveals the transformation rules from knowledge fission to knowledge fusion, which accords with the usual way we solve complex problems. Based on the simulations, we reveal the mechanism of the influence of knowledge fission and knowledge fusion on the production of a prior solution.

\subsection{Practical Implication}

First, knowledge fission has a positive influence on the production of a prior solution. Through the process of knowledge fission, IITs could generate enough ideas (prior seeds). Although not all the ideas can be developed into the final prior solution, it can guarantee a lot of good ideas are not lost, which will improve the quality and level of the prior solution to some extent. However, when the knowledge fission reaches a certain level, excessive knowledge fission has no effect on the generation of prior seeds. Instead, it is a waste of time and experience for IITs.

Second, knowledge fusion also has a positive influence on the production of a prior solution. Through the process of knowledge fusion, some bad seeds are removed and some valuable and promising seeds are improved and brought together, during which, the limited team resources are efficiently used, and team members' time and energy are saved to a large extent. 
Third, team members in IITs can carry on knowledge interaction following the above proposed model in order to avoid some bad decisions. Through the process of knowledge interaction, even if the IITs cannot obtain a prior solution to the complex problem, they can analyze and understand the problem well in order to prepare for solving the problem.

Finally, the process of knowledge interaction ensures the sustainability of the IITs. Through knowledge interaction, an adaptive prevention system and a continuous operation system can be established in the team, which ensures the benefits of the members and the team's sustainable innovation. In addition, team members can gradually find the appropriate way to interact with other members and build trust relationships, which will contribute to the knowledge interaction next time.

\subsection{Limitations and Future Research}

This paper proposed knowledge fission, knowledge fusion, and the knowledge interaction model, giving a systemic and comprehensive description on the knowledge interaction process in IITs. Based on our simulations, we now understand how knowledge fission and knowledge fusion influence knowledge interaction. As for limitations, our work only considered the influence of knowledge fission and fusion on knowledge interaction from the overall perspective. Future research should simulate more scenarios of knowledge interaction to achieve perfection.

Author Contributions: Conceptualization, Q.Z.; Methodology, X.C.; Validation, Q.Z. and X.C.; Formal Analysis, X.C.; Investigation, Q.Z. and X.C.; Data Curation, Q.Z. and X.C.; Writing-Original Draft Preparation, X.C.; Writing-Review \& Editing, Q.Z. and X.C.; Funding Acquisition, Q.Z.

Funding: This research was funded by [The National Natural Science Foundation of China] grant number [71573064, 71490724, 71273076].

Conflicts of Interest: The authors declare no conflict of interest.

\section{References}

1. Crease, R.P.; Martin, J.D.; Pesic, P. Meeting the challenge of the new big science. Phys. Perspect. 2016, 18, 247-248.

2. Memmott, R.J.; Marett, K.M.; Bott, R.L.; Duke, L. Use of the Neuman systems model for interdisciplinary teams. Online J. Rural Nurs. Health Care 2017, 1, 58-73.

3. Singh, J.; Fleming, L. Lone inventors as sources of breakthroughs: Myth or reality? Manag. Sci. 2010, 56, 41-56. [CrossRef]

4. Wuchty, S.; Jones, B.F.; Uzzi, B. The increasing dominance of teams in production of knowledge. Science 2007, 316, 1036-1039. [CrossRef] [PubMed]

5. Stehr, N.; Weingart, P. Practising Interdisciplinarity; University of Toronto Press: Toronto, ON, Canada, 2000.

6. Albanese, R.; Van Fleet, D.D. Rational behavior in groups: The free-riding tendency. Acad. Manag. Rev. 1985, 10, 244-255. [CrossRef]

7. Harkin, S.G. Social loafing and social facilitation. J. Exp. Soc. Psychol. 1987, 23, 1-18. [CrossRef]

8. Hare, A.P. Handbook of Small Group Research, 2nd ed.; The Free Press: New York, NY, USA, 1976.

9. Safoutin, M.J.; Thurston, D.L. A communications-based technique for interdisciplinary design team management. IEEE Trans. Eng. Manag. 1993, 40, 360-372. [CrossRef]

10. Campion, M.A.; Medsker, G.J.; Higgs, A.C. Relations between work group characteristics and effectiveness: Implications for designing effective work groups. Pers. Psychol. 1993, 46, 823-847. [CrossRef]

11. Stewart, G.L.; Barrick, M.R. Team structure and performance: Assessing the mediating role of intrateam process and the moderating role of task type. Acad. Manag. J. 2000, 43, 135-148.

12. Rentsch, J.R.; Delise, L.A.; Mello, A.L.; Staniewicz, M.J. The integrative team knowledge building training strategy in distributed problem-solving teams. Small Group Res. 2014, 45, 568-591. [CrossRef]

13. Todtling, F.; Lehner, P.; Kaufmann, A. Do different types of innovation rely on specific kinds of knowledge interactions? Technovation 2009, 29, 59-71. [CrossRef]

14. Fagerberg, J.; Mowery, D.C.; Edquist, C. Systems of Innovation: Perspectives and Challenges; Oxford University Press: Oxford, UK, 2009. 
15. Clark, W.C.; Tomich, T.P.; Van Noordwijk, M.; Guston, D.; Catacutan, D.; Dickson, N.M.; McNie, E. Boundary work for sustainable development: Natural resource management at the consultative group on international agricultural research (CGIAR). Proc. Natl. Acad. Sci. USA 2016, 113, 4615-4622. [CrossRef] [PubMed]

16. Paulus, P.B. Groups, teams, and creativity: The creative potential of idea-generating groups. Appl. Psychol. 2000, 49, 237-262. [CrossRef]

17. Brown, T. Design thinking. Harv. Bus. Rev. 2008, 86, 84-92. [PubMed]

18. Vasandani, V.; Govindaraj, T. Knowledge representation and human-computer interaction in an intelligent tutor for diagnostic problem-solving. In Proceedings of the 1990 IEEE International Conference on Systems, Man, and Cybernetics, Los Angeles, CA, USA, 4-7 November 1990; pp. 665-667.

19. Lee, D.S.; Lee, K.C.; Seo, Y.W.; Choi, D.Y. An analysis of shared leadership, diversity, and team creativity in an e-learning environment. Comput. Hum. Behav. 2015, 42, 47-56. [CrossRef]

20. Harvey, S. A different perspective: The multiple effects of deep level diversity on group creativity. J. Exp. Soc. Psychol. 2013, 49, 822-832. [CrossRef]

21. Farh, J.L.; Lee, C.; Farh, C.I.C. Task conflict and team creativity: A question of how much and when. J. Appl. Psychol. 2010, 95, 1173-1180. [CrossRef] [PubMed]

22. Nickerson, J.A.; Zenger, T.R. A knowledge-based theory of the firm-the problem-solving perspective. Organ. Sci. 2004, 15, 617-632. [CrossRef]

23. Harvey, S. Creative Synthesis: Exploring the Process of Extraordinary Group Creativity. Acad. Manag. Rev. 2014, 39, 324-343. [CrossRef]

24. Rietzschel, E.F.; Nijstad, B.A.; Stroebe, W. Relative accessibility of domain knowledge and creativity: The effects of knowledge activation on the quantity and originality of generated ideas. J. Exp. Soc. Psychol. 2007, 43, 933-946. [CrossRef]

25. Cropley, A. In praise of convergent thinking. Creat. Res. J. 2006, 18, 391-404. [CrossRef]

26. Zhou, J.; Hoever, I.J. Research on workplace creativity: A review and redirection. Annu. Rev. Organ. Psychol. Organ. Behav. 2014, 1, 333-359. [CrossRef]

27. Rietzschel, E.F.; Nijstad, B.A.; Stroebe, W. Productivity is not enough: A comparison of interactive and nominal brainstorming groups on idea generation and selection. J. Exp. Soc. Psychol. 2006, 42, $244-251$. [CrossRef]

28. Wang, L.; Zhang, Q.P. An agent-based simulation model for IING's adoption from a perspective of kinetic energy and potential energy. Kybernetes 2018, 47, 605-635. [CrossRef]

29. Lewin, A.Y. Research on creative and innovative management: An evaluation of research strategies. In New Directions in Creative and Innovative Management: Bridging Theory and Practice; Yuji, I., Kuhn, R.L., Eds.; Ballinger/Harper and Row: Boston, MA, USA, 1988; pp. 131-143.

30. Dougherty, D. Interpretive barriers to successful product innovation in large firms. Organ. Sci. 1992, 3, 179-202. [CrossRef]

31. O'Connor, G.C.; Rice, M.P.; Peters, L.; Veryzer, R.W. Managing interdisciplinary, longitudinal research teams: Extending grounded theory-building methodologies. Organ. Sci. 2003, 14, 353-373. [CrossRef]

32. Gardner, H.K.; Gino, F.; Staats, B.R. Dynamically integrating knowledge in teams: Transforming resources into performance. Acad. Manag. J. 2012, 55, 998-1022. [CrossRef]

33. Cardinal, L.B.; Turner, S.F.; Fern, M.J.; Burton, R.M. Organizing for product development across technological environments: Performance trade-offs and priorities. Organ. Sci. 2011, 22, 1000-1025. [CrossRef]

34. Edmondson, A.C. Speaking up in the operating room: How team leaders promote learning in interdisciplinary action teams. J. Manag. Stud. 2003, 40, 1419-1452. [CrossRef]

35. Yu, L.T.; Zellmer-Bruhn, M. Introducing team mindfulness and considering its safeguard role against conflict transformation and social undermining. Acad. Manag. J. 2018, 61, 324-347. [CrossRef]

36. Maltarich, M.A.; Kukenberger, M.; Reilly, G.; Mathieu, J. Conflict in teams: Modeling early and late conflict states and the interactive effects of conflict processes. Group Organ. Manag. 2018, 43, 6-37. [CrossRef]

37. Volkova, E.E.; Dubrovsky, V.Z.; Yaroshevich, N.Y. Modelling uncertainty-exposed team decision-making in multi-agent system. Int. J. Appl. Math. Stat. 2017, 56, 29-45.

38. Johnson, K.; Hays, C.; Center, H.; Daley, C. Building capacity and sustainable prevention innovations: A sustainability planning model. Eval. Program Plan. 2004, 27, 135-149. [CrossRef]

39. McGreavy, B.; Lindenfeld, L.; Bieluch, K.H.; Silka, L.; Leahy, J.; Zoellick, B. Communication and sustainability science teams as complex systems. Ecol. Soc. 2015, 20, 2. [CrossRef] 
40. Ceptureanu, S.I.; Ceptureanu, E.G.; Luchian, C.E.; Luchian, I. Community based programs sustainability. A multidimensional analysis of sustainability factors. Sustainability 2018, 10, 870. [CrossRef]

41. Wong, Y.Y.; Chow, I.H.S.; Lau, V.P.; Gong, Y.Y. Benefits of team participative decision making and its potential to affect individual creativity. J. Appl. Soc. Psychol. 2018, 48, 369-376. [CrossRef]

42. Mehta, A.; Mehta, N. Knowledge integration and team effectiveness: A team goal orientation approach. Decis. Sci. 2018, 49, 445-486. [CrossRef]

43. Giannoccaro, I.; Massari, G.F.; Carbone, G. Team resilience in complex and turbulent environments: The effect of size and density of social interactions. Complexity 2018, 2018, 1923216. [CrossRef]

44. Schartinger, D.; Rammer, C.; Fischer, M.M.; Frohlich, J. Knowledge interactions between universities and inudstry in Austria: Sectoral patterns and determinants. Res. Policy 2002, 31, 303-328. [CrossRef]

45. Jahanshahi, A.A.; Brem, A. Sustainability in SMEs: Top management teams behavioral integration as source of innovativeness. Sustainability 2017, 9, 1899. [CrossRef]

46. Ancona, D.; Bresman, H. X-Teams: How to Build Teams That Lead, Innovate and Succeed; Harvard Business School Press: Boston, MA, USA, 2007.

47. Storto, C.L. Small group problem-solving and knowledge creation: A fuzzy cognitive maps investigation. Adv. Sci. Lett. 2016, 22, 1282-1286. [CrossRef]

48. Fleming, L. Science as a Map in Technological Search. Strateg. Manag. J. 2004, 25, 909-928. [CrossRef]

49. Henderson, R.M.; Clark, K.B. Architectural innovation: The reconfiguration of existing product technologies and the failure of established firms. Admin. Sci. Q. 1990, 35, 9-30. [CrossRef]

50. Harvey, S.; Kou, C.Y. Collective engagement in creative tasks: The role of evaluation in the creative process in groups. Admin. Sci. Q. 2013, 58, 346-386. [CrossRef]

51. Paletz, S.B.F.; Schunn, C.D. A social-cognitive framework of multidisciplinary team innovation. Top. Cogn. Sci. 2010, 2, 73-95. [CrossRef] [PubMed]

52. Johnson-Laird, P.N. Mental models in cognitive science. Cogn. Sci. 1980, 4, 71-115. [CrossRef]

53. Super, J.F.; Li, P.S.; Ishqaidef, G.; Guthrie, J.P. Group rewards, group composition and information sharing: A motivated information processing perspective. Organ. Behav. Hum. Decis. Process. 2016, 134, 31-44. [CrossRef]

54. Dreu, C.K.W.D.; Nijstad, B.A. Group creativity and innovation: A motivated information processing perspective. Psychol. Aesthet. Creat. Arts 2011, 5, 81-89. [CrossRef]

55. Dugosh, K.L.; Paulus, P.B.; Roland, E.J.; Yang, H.C. Cognitive stimulation in brainstorming. J. Personal. Soc. Psychol. 2000, 79, 722-735. [CrossRef]

56. Kohn, N.W.; Paulus, P.B.; Choi, Y.H. Building on the ideas of others: An examination of the idea combination process. J. Exp. Soc. Psychol. 2011, 47, 554-561. [CrossRef]

57. George, J.M. Creativity in Organizations. Acad. Manag. Ann. 2007, 1, 439-477. [CrossRef]

58. Paulus, P.B.; Yang, H.C. Idea generation in groups: A basis for creativity in organizations. Organ. Behav. Hum. Decis. Process. 2000, 82, 76-87. [CrossRef]

59. Dumaine, B. The Trouble with Teams. Semin. Nurse Manag. 2001, 9, 132-135.

60. Nijstad, B.A.; De Dreu, C.K.W. Creativity and group innovation. Appl. Psychol. 2002, 51, 400-406. [CrossRef]

61. Lowe, P.; Phillipson, J.; Wilkinson, K. Why social scientists should engage with natural scientists. Contemp. Soc. Sci. 2013, 8, 207-222. [CrossRef]

62. Derry, S.J.; Gernsbacher, M.A.; Schunn, C.D. Interdisciplinary Collaboration an Emerging Cognitive Science; Lawrence Erlbaum: Mahwah, NJ, USA, 2005.

63. Pentland, A. Social Physics: How Social Networks Can Make Us Smarter; The Penguin Press: New York, NY, USA, 2014.

64. Ruan, A.; Liu, S.; Fang, Z.; Xu, X. Study on development kinetic energy of Chinese industry and measure model of energy. In Proceedings of the 6th World Congress on Intelligent Control and Automation, Dalian, China, 21-23 June 2006; pp. 718-722.

65. Bratianu, C.; Andriessen, D. Knowledge as energy: A metaphorical analysis. In Proceedings of the 9th European Conference on Knowledge Management, Southampton Sloent University, Southampton, UK, 4-5 September 2008.

66. Dima, B.; Pasca, L.; Preda, C. A financial wave model for stock indices. Econ. Comput. Econ. CYB 2015, 49, 5-20. 
67. Upward, A.; Jones, P. An ontology for strongly sustainable business models: Defining an enterprise framework compatible with natural and social science. Organ. Environ. 2016, 29, 97-123. [CrossRef]

68. Osborn, A.F. Applied Imagination: Principles and Procedures of Creative Thinking; Scribner: New York, NY, USA, 1957.

69. Getzels, J.W. Creativity and intelligence: Explorations with gifted students. Am. J. Psychol. 1962, 77, 153. [CrossRef]

70. Guilford, J.P. Traits of Creativity. In Creativity E Its Cultivation; Harper \& Brothers: New York, NY, USA, 1959.

71. Brophy, D.R. Understanding, measuring, and enhancing individual creative problem-solving efforts. Creat. Res. J. 1998, 11, 123-150. [CrossRef]

72. Rickards, T.J. Creativity from a business school perspective: Past, present and future. In Nurturing and Developing Creativity: The Emergence of a Discipline; Murdoch, M.C., Isaksen, S.G., Coleman, S.E., Eds.; Ablex.: Norwood, NJ, USA, 1993; pp. 155-176.

73. Brown, V.R.; Paulus, P.B. Making group brainstorming more effective: Recommendations from an associative memory perspective. Curr. Dir. Psychol. Sci. 2002, 11, 208-212. [CrossRef]

74. Urtasun, A.A.; Luquin, A.; Garrido, J.J. Nuclear fission technology in Spain: History and social concerns. Public Underst. Sci. 2017, 26, 307-324. [CrossRef] [PubMed]

75. Raeder, J. Controlled Nuclear Fusion: Fundamentals of Its Utilization for Energy Supply; Wiley Chichester: New York, NY, USA, 1986.

76. Mcleod, P.L.; Lobel, S.A.; Cox, T.H. Ethnic diversity and creativity in small groups. Small Group Res. 1996, 27, 248-264. [CrossRef]

77. Milliken, F.J.; Bartel, C.A.; Kurtzberg, T.R. Diversity and creativity in work groups: A dynamic perspective on the affective and cognitive processes that link diversity and performance. In Group Creativity: Innovation through Collaboration; Paulus, P.B., Nijstad, B.A., Eds.; Oxford University Press: New York, NY, USA, 2003; pp. 32-62.

78. Pelled, L.H. Demographic diversity, conflict, and work group outcomes: An intervening process theory. Organ. Sci. 1996, 7, 615-631. [CrossRef]

79. Nemeth, C.J. Differential contributions of majority and minority influence. Psychol. Rev. 1986, 93, 23-32. [CrossRef]

80. Weick, K.E. Sensemaking in Organizations; Sage: Thousand Oaks, CA, USA, 1995.

81. Paulus, P.B.; Brown, V.R. Toward more creative and innovative group idea generation: A cognitive-socialmotivational perspective of brainstorming. Soc. Personal. Psychol. Compass 2010, 1, 248-265. [CrossRef]

82. Nijstad, B.A.; Stroebe, W. How the group affects the mind: A cognitive model of idea generation in groups. Pers. Soc. Psychol. Rev. 2006, 10, 186-213. [CrossRef] [PubMed]

83. Guilford, J.P. Creativity. Am. Psychol. 1950, 5, 444-454. [CrossRef] [PubMed]

84. Kameo, N. A Culture of uncertainty: Interaction and organizational memory in software engineering teams under a productivity scheme. Organ. Stud. 2017, 38, 733-752. [CrossRef]

85. Olick, J.K. States of Memory: Continuities, Conflicts, and Transformations in National Retrospection; Duke University Press: Durham, NC, USA, 2003.

86. Olick, J.K.; Robbins, J. Social memory studies: From "collective memory" to the historical sociology of mnemonic practices. Annu. Rev.Sociol. 1998, 24, 105-140. [CrossRef]

87. Amabile, T.M. Creativity in Context; Westview Press: Boulder, CO, USA, 1996.

88. Yin, R.; Thousand, S. Case Study Research: Design and Methods, 4th ed.; Sage Publications Inc.: Thousand Oaks, CA, USA, 2009.

(C) 2018 by the authors. Licensee MDPI, Basel, Switzerland. This article is an open access article distributed under the terms and conditions of the Creative Commons Attribution (CC BY) license (http:/ / creativecommons.org/licenses/by/4.0/). 